\title{
AKTIVITAS ANTIOKSIDAN EKSTRAK DAUN LIBO (Ficus variegate Blume) DENGAN BERBAGAI METODE EKSTRAKSI
}

\author{
Dian Dwi Cahyadi*, Lizma Febrina, Rolan Rusli \\ Research and Development Laboratory Farmaka Tropis, Faculty of Pharmacy, University \\ of Mulawarman, Samarinda, East Kalimantan \\ email: cajyarf03@gmail.com
}

\begin{abstract}
Libo (Ficus variegate Blume) is one of the wild plants, and the leaves were never eaten by caterpillars. At this stage, the study of the antioxidant activity of the extracts of leaves Libo various extraction methods. This study was examines differences in antioxidant activity of maceration extraction methods (no heat) and refluktation (with heat). IC 50 results of each method with DPPH (2,2-Diphenyl-1-Picrylhydrazyl) 0.04\% was 46.3 ppm for maceration and $120.9 \mathrm{ppm}$ for refluktation. It can be concluded that the heat temperature affect antioxidant activity.
\end{abstract}

Keywords: Leaves Libo IC 50 , Maceration, Refluktation

\begin{abstract}
ABSTRAK
Tumbuhan Libo (Ficus variegate Blume) merupakan salah satu tumbuhan liar, dan bagian daunnya tidak pernah dimakan oleh ulat. Pada tahap ini dilakukan kajian aktivitas antioksidan ekstrak daun libo dari berbagai metode ekstraksi. Penelitian ini mengkaji perbedaan aktivitas antioksidan dari metode ekstraksi maserasi (cara dingin) dan refluktasi (cara panas). Hasil $\mathrm{IC}_{50}$ dari masing-masing metode dengan DPPH (2,2-Diphenyl-1Picrylhydrazyl) $0,04 \%$ adalah 46,3 ppm untuk maserasi dan 120,9 ppm untuk refluktasi. Dapat disimpulkan bahwa suhu pemanasan mempengaruhi aktivitas antioksidan.
\end{abstract}

Kata Kunci : Daun Libo, $\mathrm{IC}_{50}$, Maserasi, Refluktasi

\section{PENDAHULUAN}

Radikal bebas diartikan sebagai molekul yang mempunyai satu atau lebih elektron yang tidak berpasangan di orbit luarnya sehingga relatif tidak stabil. Untuk mendapatkan kestabilannya, molekul yang bersifat reaktif tersebut mencari pasangan elektronnya, sehingga disebut juga sebagai Reactive Oxygen Species [1]. Senyawa yang dapat menstabilkan radikal bebas adalah antioksidan. Senyawa ini dapat menghambat reaksi berantai dari pembentukan radikal bebas [2]. Antioksidan bekerja dengan cara mendonorkan satu elektronnya kepada senyawa yang bersifat oksidan sehingga aktivitas senyawa oksidan tersebut bisa dihambat [3].

Meningkatnya penelitian dalam menemukan antioksidan alami untuk kosmetik, makanan, atau obat-obatan untuk menggantikan antioksidan sintesis, disebabkan penggunaan antioksidan sintesis telah dibatasi karena efek samping yang dimiliki. Selain itu antioksidan alami lebih dipertimbangkan karena lebih aman, stabil, dan efek antioksidan yang lebih baik [4]. Salah satu sumber tumbuhan obat yang berpotensi sebagai antioksidan alami adalah tumbuhan Libo (Ficus variegata Blume) [5]. 
Ada pun cara untuk memperoleh antioksidan alami tersebut adalah melalui penyarian atau ekstraksi. Metode ekstraksi pun berbeda-beda ada yang dipercepat proses ekstraksinya menggunakan suhu yang lebih tinggi atau pemanasan (cara panas) ada yang tidak (cara dingin). Antioksidan bersifat sensitif terhadap cahaya dan panas, oleh karena itu penanganan bahan baku sumber antioksidan harus baik dan dihindarkan dari berbagai faktor yang dapat menurunkan aktivitasnya.

Penelitian ini bertujuan untuk mengkaji aktivitas antioksidan ekstrak daun Libo dari berbagai metode ekstraksi yaitu maserasi (cara dingin) dan refluktasi (cara panas).

\section{METODE PENELITIAN}

\section{Bahan}

Bahan yang digunakan dalam penelitian ini adalah: daun Libo (Ficus varigate Blume) yang diperoleh dari Samarinda, Kalimantan Timur, DPPH (1,1-difenil-2-pikrilhidrazil), metanol, kertas saring.

\section{Peralatan}

Alat yang digunakan dalam penelitian ini adalah: almari pengering, corong Buchner, vacuum rotary evaporator, neraca analitik, spektrofotometer UV-VIS, mikropipet 100$1000 \mu \mathrm{L}$, blue tip, dan alat-alat gelas yang lazim digunakan di laboratorium analisis.

\section{Prosedur}

\section{Penyiapan Sampel}

Daun Libo yang diambil adalah bagian daun yang masih utuh, hijau, segar, kemudian dikumpulkan dan dipisahkan dengan pengotor lainnya seperti tanah, bagian bukan daun atau bagian tanaman yang rusak. Setelah itu sampel ditimbang kembali, selanjutnya sampel dicuci bersih dengan air mengalir untuk menghilangkan dari kotoran yang melekat pada daun. Dipotong kecil-kecil sesuai derajat yang diinginkan. Kemudian dikeringkan diudara terbuka terlindung dari sinar matahari.

\section{Ekstraksi Sampel}

Simplisia kering yang sudah dihaluskan, kemudian diekstraksi menggunakan dua metode, yaitu cara panas dan cara dingin. Maserasi mewakili cara dingin sementara refluktasi mewakili cara panas.

\section{a. Metode Ekstraksi Maserasi}

Sebanyak 10 gram serbuk daun libo dibungkus menggunakan kertas saring, kemudian dimasukkan kedalam botol gelap, tambahkan pelarut metanol $100 \mathrm{~mL}$. Rendam selama 1 hari sambil sesekali diaduk, kemudian bungkus serbuk daun libo tersebut diambil. Filtrat yang diperoleh kemudian dipekatkan dengan menggunakan rotary evaporator pada suhu $40{ }^{\circ} \mathrm{C}$.

b. Metode Ekstraksi Refluktasi

Dipasang alat refluk, kemudian masukkan serbuk daun libo yang telah dibungkus dengan kertas saring ke dalam alat refluk, masukkan pelarut metanol $100 \mathrm{~mL}$. Lakukan proses refluktasi pada suhu $70{ }^{\circ} \mathrm{C}$. Waktu ekstraksi dilakukan hingga 6 jam. Ekstrak cair yang diperoleh kemudian dipekatkan dengan menggunakan rotary evaporator dengan suhu $40{ }^{\circ} \mathrm{C}$.

Hitung hasil rendamen ekstrak metanol daun libo dengan rumus sebagai berikut :

$\%$ Rendamen $=\frac{\text { jumlah berat sampel hasil }}{\text { jumlah berat sampel awal }} \times 100 \%$ 


\section{Uji Aktivitas Antioksidan}

a. Penentuan seri konsentrasi

Ekstrak dari masing-masing metode ekstraksi ditimbang sejumlah 10 mg kemudian dilarutkan dengan metanol pada labu ukur hingga $100 \mathrm{~mL}$ diperoleh konsentrasi $100 \mathrm{ppm}$ (larutan stok). Kemudian dari larutan tersebut dibuat 5 konsentrasi (5, 10, 20, 40, 80 ppm) dan masing-masing konsentrasi dibuat 3 replikasi.

b. Pengukuran Absorbansi

Pengukuran aktivitas antioksidan adalah dengan menggunakan spektrofotometer UVVis. Masing-masing konsentrasi diukur serapannya dengan menggunakan spektrofotometer UV-Vis pada panjang gelombang $515 \mathrm{~nm}$ serta membandingkan dengan blanko yaitu metanol.

c. Penentuan \% Inhibisi dan IC50

Besarnya aktivitas antioksidan dihitung dengan menggunakan rumus:

$(\%$ Inhibisi $)=\frac{(\text { Abs. kontrol }- \text { Abs. sampel })}{\text { Abs kontrol }} \times 100 \%$

Data absorbansi yang diperoleh dibuat persamaan regresi linear yang menyatakan hubungan antara konsentrasi bahan uji (x) dengan aktivitas antioksidan rata-rata (y) dari suatu seri replikasi pengukuran sehingga diperoleh harga IC50 yaitu konsentrasi bahan uji yang diperlukan untuk menangkap 50\% radikal DPPH selama 30 menit (operating time), atau jeda waktu yang dibutuhkan oleh bahan uji untuk mereduksi radikal DPPH dengan sempurna.

\section{HASIL DAN PEMBAHASAN}

Ekstraksi yang dilakukan pada daun libo menggunakan cara panas dan cara dingin. Meserasi mewakili cara dingin sedangkan refluktasi mewakili cara panas. Keuntungan metode ekstraksi maserasi adalah prosedur dan peralatan yang digunakan sederhana, metode ini tidak dipanaskan sehingga bahan alam yang dikandungnya tidak terurai, sedangkan metode ekstraksi cara panas (refluktasi) memiliki keuntungan yaitu waktu yang digunakan lebih cepat. Selain itu aktivitas biologis tidak hilang saat dipanaskan.

Tabel 1. Hasil Rendamen Ekstrak Daun Libo

\begin{tabular}{cccc}
\hline Metode Ekstraksi & $\begin{array}{c}\text { Berat Simplisia } \\
\text { (gram) }\end{array}$ & $\begin{array}{c}\text { Berat Ekstrak } \\
\text { (gram) }\end{array}$ & \% Rendamen \\
\hline Maserasi & 10,005 & 0,25 & 2,49 \\
Refluktasi & 10,004 & 0,2882 & 2,88 \\
\hline
\end{tabular}

Tabel 2. Pengujian aktivitas antioksidan ekstrak dari refluktasi

\begin{tabular}{cccccc}
\hline Konsentrasi & $\mathrm{R} 1$ & $\mathrm{R} 2$ & $\mathrm{R} 3$ & Absorbansi & \% Inhibisi \\
\hline 10 & 0,584 & 0,583 & 0,586 & 0,584 & 6,858 \\
20 & 0,564 & 0,564 & 0,570 & 0,566 & 9,729 \\
40 & 0,525 & 0,525 & 0,521 & 0,524 & 16,427 \\
80 & 0,429 & 0,425 & 0,421 & 0,425 & 32,217 \\
100 & 0,365 & 0,363 & 0,345 & 0,356 & 43,222 \\
\hline
\end{tabular}


Tabel 3. Pengujian aktivitas antioksidan ekstrak dari maserasi

\begin{tabular}{cccccc}
\hline Konsentrasi & $\mathrm{R} 1$ & $\mathrm{R} 2$ & $\mathrm{R} 3$ & Absorbansi & \% Inhibisi \\
5 & 0,582 & 0,580 & 0,590 & 0,584 & 4,731 \\
10 & 0,536 & 0,535 & 0,538 & 0,536 & 12,561 \\
20 & 0,464 & 0,468 & 0,472 & 0,468 & 23,654 \\
40 & 0,322 & 0,315 & 0,323 & 0,320 & 47,798 \\
80 & 0,107 & 0,111 & 0,103 & 0,107 & 82,545 \\
\hline
\end{tabular}

Tabel 1 menunjukkan bahwa ekstrak dari metode refluktasi (cara panas) menghasilkan \% rendemen yang lebih besar dibandingkan meserasi (cara dingin). Hal ini disebabkan oleh suhu pemanasan yang digunakan. Karena suhu dapat mempengaruhi tingkat kelarutan suatu bahan atau senyawa.

Uji aktivitas antioksidan ekstrak daun Libo dengan menggunakan metode DPPH untuk mengukur kemampuan suatu senyawa antioksidan dalam menangkap radikal bebas. Kemampuan penangkapan radikal berhubungan dengan kemampuan komponen senyawa dalam menyumbangkan elektron atau hidrogen. Setiap molekul yang dapat menyumbangkan elektron atau hidrogen akan bereaksi dan akan memudarkan DPPH. Intensitas warna DPPH akan berubah dari ungu menjadi kuning oleh elektron yang berasal dari senyawa antioksidan. Konsentrasi DPPH pada akhir reaksi tergantung pada konsentrasi awal dan struktur komponen senyawa penangkap radikal [6].

Pada tabel 2 dan 3 menunjukkan pengujian aktivitas antioksidan dari ekstrak yang telah diperoleh. $\mathrm{IC}_{50}$ dari ekstrak maserasi dan refluktasi yang dapat terlihat pada gambar 1 dan 2 adalah 46,3 ppm dan 120,9 ppm. Terlihat perbedaan aktivitas antioksidan antara maserasi dan refluktasi. Tingkat kekuatan antioksidan adalah kuat $\left(\mathrm{IC}_{50}<50 \mathrm{ppm}\right)$, aktif ( $\mathrm{IC}_{50}$ 50-100 ppm), sedang ( $\mathrm{IC}_{50}$ 101-250), lemah (IC S0 $_{250-500)}$ dan tidak aktif $\left(\mathrm{IC}_{50}>500 \mathrm{ppm}\right)$ [7]. Dapat disimpulkan bahwa ekstrak maserasi lebih tinggi saktivitasnya dibandingkan ekstrak refluktasi.

Pada tabel 1 menunjukkan bahwa ekstrak refluktasi menghasilkan jumlah ekstrak terbanyak namun pada gambar 1 dan 2 menunjukkan bahwa ekstrak yang memiliki aktivitas antioksidan terbaik adalah maserasi. Perbedaaan tersebut dikarenakan hilangnya kadar beberapa senyawa aktif antioksidan terurai atau terdegradasi oleh suhu pemanasan yang digunakan pada proses ekstraksi.

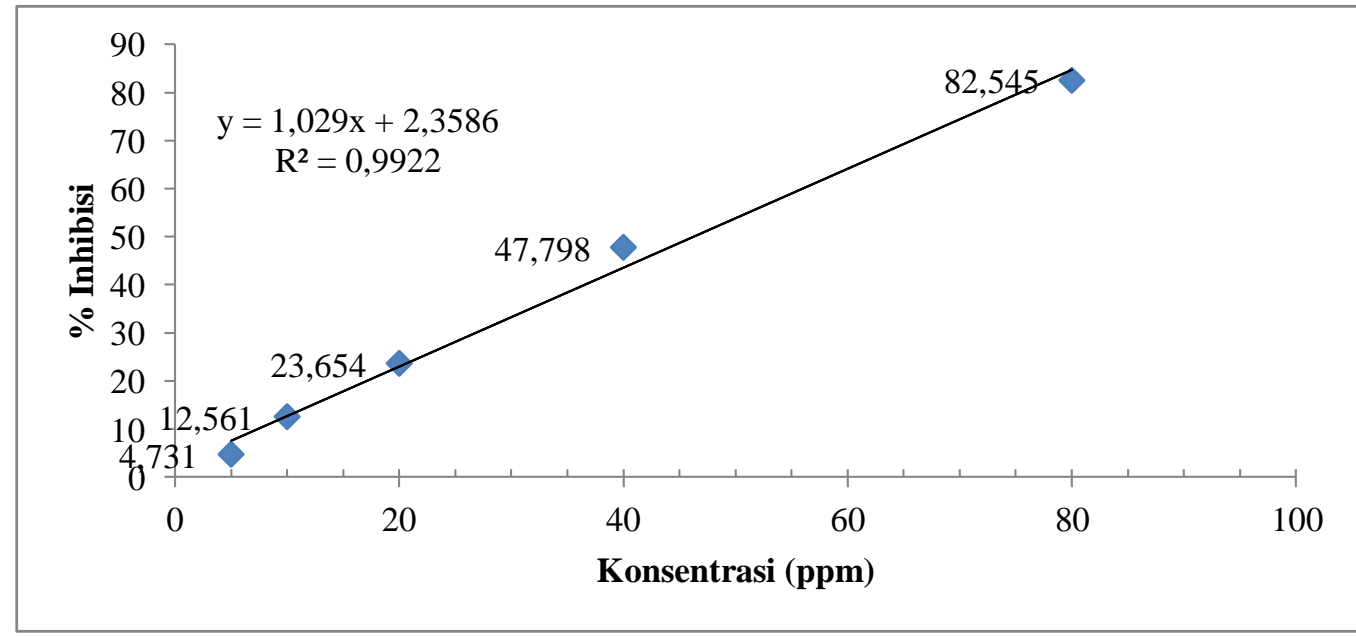

Gambar 1. Pengujian Aktivitas Antioksidan Ekstrak Maserasi 


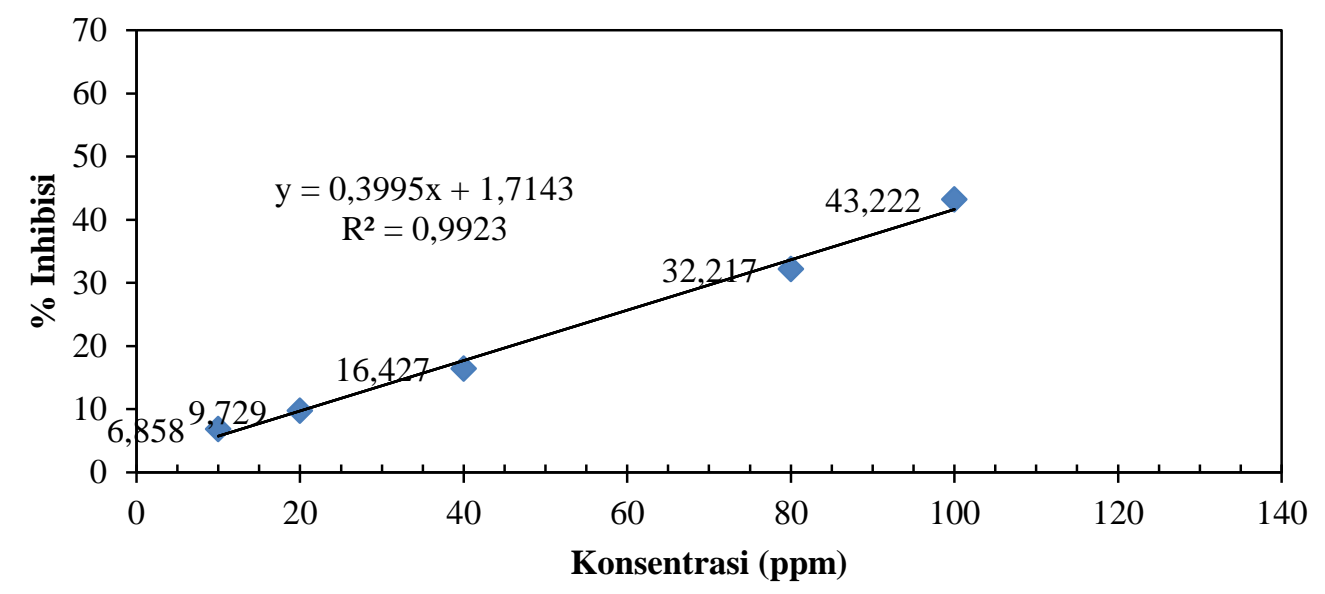

Gambar 2. Pengujian Antioksidan Ekstrak Refluktasi

\section{KESIMPULAN}

$\mathrm{IC}_{50}$ dari ekstrak maserasi dan refluktasi berturut-turut sebesar 46,3 ppm dan 120,9 ppm. Penggunaan metode ekstraksi yang berbeda menghasilkan aktivitas yang berbeda pula. Metode ekstraksi terbaik untuk mendapatkan aktivitas antioksidan terbaik adalah metode maserasi (cara dingin).

\section{DAFTAR PUSTAKA}

1. Ardie, Ari Muhandari. 2011.Radikal Bebas dan Peran Antioksidan dalam Mencegah Penuaan. Medicinus 24(1).

2. Hudson, B. J. F, 1990, Food Antioxidants, Elsevier Applied Science, New York.

3. Winarsi, H. 2007. Antioksidan Alami dan Radikal Bebas Potensi dan Aplikasi dalam Kesehatan. Kanisius: Yogyakarta.

4. Zheng W, Wang SY. 2001. Antioxidant Activity and Phenolic Compounds in Selected Herbs. J Agric Food Chem 49:5165-5170.

5. Rijai, Laode. 2013. Potensi Tumbuhan Libo (Ficus variegata Blume.) Sebagai Sumber Bahan Farmasi Potensial. Journal of Tropical Pharmacy and Chemistry, 2. (3). 166179. DOI: https://doi.org/10.25026/jtpc.v2i3.63

6. Naik, G.H., Priyadarsini, K.I., Satav, J.G., Banavalikar, M.M., Sohoni, D.P., Biyani, M.K., and Mohan H., 2003, Comparative antioxidant activity of individual herbal components used in ayurvedic medicine, Phytochemistry, 63 (1): 97-104

7. Jun, M.H.Y., J., Fong, X., Wan, C.S., Yang, C.T., Ho. 2003. Camparison of Antioxidant Activities of Isoflavones Form Kudzu Root (Puerarua labata O). Journal Food Science Institute of Technologist. 68:2117-2122. 